\title{
Prognostic significance of HLA EMR8-5 immunohistochemically analyzed expression in osteosarcoma
}

\author{
Ola H Nada ${ }^{1 *}$, Naglaa S Ahmed ${ }^{2 \dagger}$ and Hoda H Abou Gabal ${ }^{3+}$
}

\begin{abstract}
Background: Defects in Human Leukocyte Antigen (HLA) class I antigen expression and/or function in tumor cells have been extensively investigated, because of their potential role in the escape of tumor cells from T cell recognition and destruction. The researchers evaluated HLA class I expression in tumor tissue as a prognostic factor in osteosarcoma patients and as a predictor of their survival. This retrospective cohort study was conducted at the pathology laboratory of Ain Shams University Hospital, and Ain Shams University Specialized Hospital during the period between January 2009 and January 2012.
\end{abstract}

Methods: The researchers investigated HLA class I expression in primary osteosarcoma by immunohistochemistry using EMR8-5 mAbs. Furthermore, researchers evaluated the correlation between HLA class I expression and the clinicopathological status and outcome in formalin fixed paraffin embedded tissues from thirty six (36) patients with osteosarcoma.

Results: A high expression of HLA class I was detected in 18 (50) \% of tumor samples examined; while tumors with low or negative expression represented $9(25 \%)$ cases each. Data indicate that the overall survival rate of patients with tumors highly expressing HLA class I was significantly higher than those with low or negative expression.

Conclusion: Down-regulation of class I antigen expression is associated with features of aggressive disease and a poorer prognosis. Therefore, it is imperative to identify HLA as a prognostic factor at the time of diagnosis to detect chemotherapy-resistant tumors and to generate a modified treatment regimen.

Virtual slides: The virtual slides for this article can be found here: http://www.diagnosticpathology.diagnomx.eu/vs/ 1159334857109547.

Keywords: Osteosarcoma, Human leukocyte antigen, Prognostic factors, Immunohistochemistry

\section{Introduction}

Osteosarcoma (OS) is the most common primary malignant bone tumor in children and adolescents with a high metastatic potential $[1,2]$ comprising approximately $20 \%$ of overall bone tumors and about $5 \%$ of pediatric tumors $[3,4]$. OS is the fifth most common malignancy among individuals aged 15 to 19 years, and the second most common in adolescents after lymphoma. The incidence of osteosarcoma in the general population is $2-3$ million/

\footnotetext{
*Correspondence: dr_olanada@yahoo.com

${ }^{\dagger}$ Equal contributors

'Department of pathology, faculty of Medicine, Ain Shams university, Cairo, Egypt

Full list of author information is available at the end of the article
}

year, but is higher in adolescence, in which the annual incidence peaks at 8-11 million/year at 15-19 years of age [5]. Boys are reported to be affected more frequently than girls [6].

Osteosarcoma occurs primarily in the metaphysis of long bones around the knee region of the distal femur or proximal tibia in about $80 \%$ of cases. In the remaining $20 \%$ of the cases, OS occurs in the axial skeleton and pelvis [5,7]. Commonly affected bones, in descending order, are the femur (40\%), the tibia (20\%) and humerus (10\%) [8]. OS is a highly aggressive neoplasm having a broad spectrum of histologic appearances. Depending on the predominant type of extracellular matrix, conventional osteosarcoma is classified into osteoblastic, chondroblastic 
and fibroblastic [9]. This separation is largely artificial, because there is no statistical difference in the survival of patients with high-grade tumors among these 3 histologic types. Moreover, the treatment for all types is similar [10].

The 5-year event-free survival rate for patients with localized disease has reached $70 \%$ [11], in contrast to $20 \%$ for patients with metastatic osteosarcoma [12,13]. Until recently, both types of patients have been treated using the same therapy according to the discretion of physicians. This signifies that these patients do not usually receive consistent and homogenous treatment. Fifty percent of patients with osteosarcoma of the extremity can be cured with a relatively nonaggressive regimen of chemotherapy [14]. One-third of patients with localized osteosarcoma experience recurrent or progressive disease $[15,16]$ and the average survival period after a recurrence is $<1$ year [17]. Therefore, to improve the survival rate of osteosarcoma patients and to improve their overall wellbeing, it is imperative to develop continuously novel therapeutic strategies and prognostic markers to define different risk groups [18].

A number of clinical and pathologic features such as clinical stage have been reported to be correlated with survival [19] in addition to patient's age and gender [20], tumor site [21], type of surgery [22], and local recurrence. The histologic response of the tumor, identified by the degree of necrosis, to the preoperative chemotherapy is currently the most sensitive indicator of survival [21]. Moreover, serological and molecular markers, such as alkaline phosphatase and lactate dehydrogenase, p-glycoprotein, cxcr4, survivin, and ezrin, are powerful predictors of survival for patients with osteosarcoma [23]. Nonetheless, individually, these prognostic factors have limited utility in predicting survival [24]. Recently, research on osteosarcoma has focused on identifying novel therapeutic targets and prognostic markers. Several molecular targets are currently under evaluation for osteosarcoma. There is, however, insufficient data to allow any of these targets to be recommended as prognostic factors or therapeutic targets [25].

Recently, immunotherapeutic trials have been suggested and conducted for bone tumors; including human leukocyte antigen (HLA) class I antigens. HLA class I antigens are trans-membrane glycoproteins expressed on the surface of most nucleated cells in the human body [26]. They have a central role in the cell-mediated immune system. Cytotoxic T lymphocytes (CTLs) can recognize antigenic peptides presented on the cell surface with HLA class I molecules, and kill the target cell, thus allowing the destruction of tumor cells by the immune system [27]. Down-regulation of HLA class I was found to be implicated in the immune escape of malignant tumors [28]. In addition, the frequency of HLA class I defects is reportedly higher in metastatic lesions than in primary or premalignant lesions [26]. Independent of the traditional prognostic markers for these cancers, HLA class I antigen down-regulation as a biomarker has also been shown to have prognostic powers in breast, esophageal cancer [29], malignant melanoma [30], lung [26], ovarian cancers [31], colon cancer [32] and renal cell carcinoma [33]. As such, it affects survival of patients with these diseases [27]. The loss of HLA class I molecules has been discussed in the context of tumor aggressiveness, such as differentiation of histology, invasiveness, and metastatic potential [34,35].

The major goals of cancer biology studies are to identify prognostic factors and therapeutic targets. Gene and protein expression array data may soon provide customized information on tumor prognosis and metastatic potential, as well as indications of possible tumor targets for selective therapy. The objective of this study is to evaluate HLA class I EMR8-5 as a potential prognostic factor in osteosarcoma patients at time of diagnosis that is capable of predicting their survival.

\section{Material and methods}

This is a retrospective cohort study, which includes formalin fixed paraffin embedded tissue blocks from 36 patients with osteosarcoma, for whom medical records were archived in the pathology laboratory of Ain Shams University Hospital, and Ain Shams University Specialized Hospital during the period between January 2009 and January 2012. This study obtained the institutional review board approval from Research Ethical Committee at Faculty of Medicine, Ain Shams University. Written informed consent was obtained from the patients for the publication of this report and any accompanying images.

Inclusion criteria for selecting the tumor tissue blocks are as follows: (1) Tumor is a primary osteosarcoma located in the extremity; (2) Age of the Patients is under 40, having received chemotherapy and limb salvage; (3) Archival paraffin embedded tissue of the pretreatment diagnostic biopsy and the resection specimen are available; (4) Resectable metastatic nodules in non-localized osteosarcoma; and (5) Clinical follow up data after initial diagnosis is available.

Clinic-pathologic variables were recorded and included age, gender, tumor location, maximal tumor diameter on initial magnetic resonance images, histologic subtype and status of stage (localized versus metastasis) at time of diagnosis. Also, laboratory results for serum alkaline phosphatase at presentation and follow up data, starting from the time of initial biopsy until the death of the patients, disease occurrence in any site (distant metastases or local recurrence) or the last follow up were also recorded. Survival indicators (the overall survival and disease free survival) were identified from the follow up data.

Paraffin embedded tissue blocks of the pretreatment diagnostic biopsy and the post treatment primary resection specimens of 36 osteosarcoma cases were cut at 4 
microns thick sections and subjected to the following examinations:

\section{Routine haematoxylin and eosin staining}

$\mathrm{H}$ \& $\mathrm{E}$ stained slides of the initial pretreatment biopsies were examined and revised to evaluate the histopathologic type and tumor grade, which is based on the recent WHO criteria for histopathologic classification. The posttreatment primary resection specimens were examined for the evaluation of the histologic response of the preoperative chemotherapy. The results were considered good if the extent of tumor necrosis was $\geq 90 \%$ and poor if it was $<90 \%$.

\section{Immunohistochemical staining for HLA EMR8-5 for sections of the pretreatment diagnostic biopsies}

Tissue sections were deparaffinized, rehydrated then endogenous peroxidase activity was quenched by $10 \mathrm{~min}$ incubation in 3\% hydrogen peroxide in methanol. After antigen retrieval and protein block, the primary antibody [Mouse monoclonal [EMR8-5] to HLA Class $1 \mathrm{ABC}$, diluted by PBS, 1:100, Abcam, Catalog No. ab70328] was applied using Sequenza center for immunostaining. The secondary antibody (supersensitive immunodetection system (Biogenex, catalog No: AD000-SL) was then applied followed by peroxidase labeled streptavidin. Slides were incubated for 10 minutes with substrate chromogen (DAB) mixture. Finally, the slides were counterstained and mounted with Canada balsam. Colon carcinoma tissue sections were used as positive control. Both positive and negative control slides were included in each run.

All specimens were reviewed independently using light microscopy for at least five areas at a $400 \times$ magnification by the investigators, blinded with respect to the immunohistologic and clinical data. The reactivity of HLA class I EMR8-5 was determined by staining of the plasma membranes of tumor cells. The expression status of HLA class I was graded semiquantitatively according to the following modified classification: negative (positive cells $<5 \%$ ), low ( $\leq 5 \%$ positive cells $\leq 50 \%$ ), and high (positive cells $>50 \%$ ). Diffuse expression and heterogeneous expression were regarded as high grade and low grade, respectively. Focal expression was graded as low or negative according to the percentage of positive cells [36].

\section{Statistical analysis}

The data collected was revised, coded, tabulated and introduced to a PC using Statistical Package for Social Science (SPSS 15.0.1 for windows; SPSS Inc, Chicago, IL, 2001). Continuous variables are expressed as mean and SD. Categorical variables are expressed as frequencies and percentages. Student T Test was used to assess the statistical significance of the difference between two study group means. ANOVA Test was used to assess the statistical significance of the difference between more than two study groups mean. Fisher's exact test was used to examine the relationship between Categorical variables when the expected count is less than 5 in more than $20 \%$ of cells. The endpoints of this study were both disease-free survival and overall survival. Disease-free survival is defined as the period as of the date of initial biopsy until disease occurrence (distant metastases or local recurrences) or last follow up. Overall survival is defined as the period lapsing from the date of initial biopsy until death or last follow. Patients who remained alive at the time of data cut-off were censored at the last date the patient was known to be alive. Survival distributions were estimated using the Kaplan-Meier method. Correlations between survival and potential prognostic features were analyzed using the log-rank test. Cox Regression was used for modeling the time to a specified event, taking into consideration the values of other given variables. Univariate and multivariable analyses of the postoperative outcome were conducted using Cox's proportional hazards model. P- Value (level of significance) $<0.05$ is designed as Significant (S) while $P=.01$ denotes highly significant (HS).

\section{Results}

\section{Results of the clinicopathological data collected}

Among the 36 studied cases, 27 (75\%) were male and 9 (25\%) were female, at a proportion of 3:1. The age ranges from 12 to 28 years, with a mean of $15.42 \pm 4.17$ years. Eighteen patient $(50 \%)$ were $\leq 14$ years and 18 patients $(50 \%)$ were $>14$ years. Regarding the anatomical location of the tumor, 27 (75\%) tumors were in the femur, particularly in its distal third 21 (58.3\%), while the remaining nine tumors were located in the tibia (25\%). The size of these tumors ranged from 8.5 to $20 \mathrm{~cm}$ with a mean of $11.82 \pm$ 4.54. Preoperative computed tomography demonstrated metastasis in nine patients (25\%).

\section{Results of the examination of haematoxylin and Eosin tissue sections}

Evaluation of the histopathological sections revealed that osteosarcoma variants were subdivided into 12 (33.3\%) chondroblastic, 9 (25\%) fibroblastic, 12 (33.3\%) osteoblastic and 3 (8.3\%) small-cell tumors. By examination of postoperative tissue sections from primary resection specimens for tumor necrosis, researchers found that 24 (66.7\%) responded poorly to preoperative chemotherapy, whereas only 12 (33.3\%) of the tumors responded well.

\section{Results of the expression of HLA class I in osteosarcoma}

Immunohistochemical staining was evaluated and out of the 36 osteosarcoma specimens, 18 (50\%) were graded as having high expression of HLA class I molecules; 9 specimens (25\%) were graded as having low expression; and the remaining 9 specimens $(25 \%)$ were negative for 
HLA class I expression. Collectively, the expression of HLA class I was lost (negative-grade expression) or down regulated (low-grade expression) in $50 \%$ of the tumor tissues.

There were significant statistical differences in the distribution of immunohistochemical scores of HLA class I among the different tumor stages at the time of presentation (localized stage versus metastases stage) $(\mathrm{P}=.0001)$. Negative HLA class I was observed significantly more often, in cases with metastatic disease compared to cases without metastases. None of the metastatic cases at time of diagnosis showed high HLA class I expression (Table 1). A highly significant relationship was also found between HLA class I expression and the sex of the patients $(\mathrm{P}=.000)$; all cases showing high HLA class I expression were males (Table 1). Similarly a highly significant association was noted between HLA class I expression and histopathological variants $(\mathrm{P}=.0001)$. Nonetheless, the relationships of the other clinicopathological parameters including age, tumor site, serum ALP at time of presentation, extent of tumor necrosis were statistically insignificant (Table 1).

\section{HLA class I expression relating to survival in primary osteosarcoma}

To investigate the relationship between HLA class I expression and the clinical outcome, researchers analyzed patient survival relating to HLA class I expression in the primary tumor. The duration of follow-up for the entire study group ranged from 12 to 50 months with the mean of $29.8 \pm 7.3$ months and median of 30 months, during which 8 patients (22.2\%) died of disease; length of survival ranged from 12-36 months with mean of $24.6 \pm 8.1$ months and median of 27 months. Twenty-three patients (63.8\%) developed a disease (relapse), either metastatic disease or local recurrences; interval to disease recurrence ranged from 2-40 months with a mean of $12.1 \pm 9$ months and median of 10 months. The overall survival rate at 1, 2 and 3 year was $97.2 \%, 91.7 \%$ and $65.5 \%$ respectively; with a mean of $42.4 \pm 2.4$ months. However, the disease-free survival at 1, 2 and 3 year was $58 \%, 41.7 \%$ and $38.9 \%$ respectively; with a mean of $24.3 \pm 3$ months and a median of 18 months.

Through the use of univariate analysis of the overall and the disease free survival in relation to the HLA class I expression (Table 2), Log Rank tests performed on Kaplan - Meier survival curves disclosed a highly significant differences in overall and disease free survival ( $\mathrm{P}=.0001$ for both) (Figures 1 and 2). Patients who had high expression of HLA class I in their initial biopsies showed a significant better overall survival compared to those with low expression of HLA class I, or those with negative expression. As regards the disease free survival, patients with osteosarcoma highly expressing HLA class I had a significantly better disease-free survival compared to those with negative expression. Similarly, osteosarcomas

Table 1 Comparison of the clinical characteristics of studied 36 cases with HLA class I expression

\begin{tabular}{|c|c|c|c|c|c|c|c|c|c|}
\hline & & \multicolumn{6}{|c|}{ HLA class I expression } & \multirow{3}{*}{$\mathbf{P}$} & \multirow{3}{*}{ Sig } \\
\hline & & \multicolumn{2}{|c|}{ Negative } & \multicolumn{2}{|c|}{ Low } & \multicolumn{2}{|c|}{ High } & & \\
\hline & & $\mathbf{N}$ & $\%$ & $\mathbf{N}$ & $\%$ & $\mathbf{N}$ & $\%$ & & \\
\hline \multirow{2}{*}{ Age group } & $\leq 14$ years & 3 & $33.3 \%$ & 6 & $66.7 \%$ & 9 & $50.0 \%$ & \multirow{2}{*}{$.473^{*}$} & \multirow{2}{*}{ NS } \\
\hline & $>14$ years & 6 & $66.7 \%$ & 3 & $33.3 \%$ & 9 & $50.0 \%$ & & \\
\hline \multirow{2}{*}{ Sex } & Male & 6 & $66.7 \%$ & 3 & $33.3 \%$ & 18 & $100.0 \%$ & \multirow{2}{*}{$.0001^{*}$} & \multirow{2}{*}{$\mathrm{HS}$} \\
\hline & Female & 3 & $33.3 \%$ & 6 & $66.7 \%$ & 0 & $.0 \%$ & & \\
\hline \multirow{2}{*}{ Tumor stage at diagnosis } & Localized & 3 & $33.3 \%$ & 6 & $66.7 \%$ & 18 & $100.0 \%$ & \multirow{2}{*}{$.0001^{*}$} & \multirow{2}{*}{ HS } \\
\hline & Metastatic & 6 & $66.7 \%$ & 3 & $33.3 \%$ & 0 & $.0 \%$ & & \\
\hline \multirow{3}{*}{ Tumor site } & Lower femur & 3 & $33.3 \%$ & 6 & $66.7 \%$ & 12 & $66.7 \%$ & \multirow[t]{3}{*}{$.250^{*}$} & \multirow[t]{2}{*}{ NS } \\
\hline & Middle femur & 3 & $33.3 \%$ & 0 & $.0 \%$ & 3 & $16.7 \%$ & & \\
\hline & Upper tibia & 3 & $33.3 \%$ & 3 & $33.3 \%$ & 3 & $16.7 \%$ & & \\
\hline \multirow{2}{*}{ Tumor necrosis } & Poor response & 8 & $88.9 \%$ & 6 & $66.7 \%$ & 10 & $55.6 \%$ & \multirow{2}{*}{$.258^{*}$} & \multirow{2}{*}{ NS } \\
\hline & Good response & 1 & $11.1 \%$ & 3 & $33.3 \%$ & 8 & $44.4 \%$ & & \\
\hline \multirow{4}{*}{ Histopathological variant } & Chondroblastic & 3 & $33.3 \%$ & 6 & $66.7 \%$ & 3 & $16.7 \%$ & \multirow{4}{*}{$.0001^{*}$} & \multirow{4}{*}{ HS } \\
\hline & Fibroblastic & 0 & $.0 \%$ & 0 & $.0 \%$ & 9 & $50.0 \%$ & & \\
\hline & Osteoblastic & 6 & $66.7 \%$ & 0 & $.0 \%$ & 6 & $33.3 \%$ & & \\
\hline & Small cell & 0 & $.0 \%$ & 3 & $33.3 \%$ & 0 & $.0 \%$ & & \\
\hline Serum alkaline phosphatase & Mean $\pm S D$ & 592.1 & 372.6 & 482.5 & 298.9 & 324.0 & 228.8 & $.078^{* *}$ & NS \\
\hline
\end{tabular}


Table 2 Univariate survival analysis of osteosarcoma according to immunohistochemistry scores for HLA class I and other clinicopathologic factors

\begin{tabular}{|c|c|c|}
\hline & $\begin{array}{l}3 \text { year overall } \\
\text { survival rate }\end{array}$ & $\begin{array}{l}3 \text { year disease } \\
\text { free survival rate }\end{array}$ \\
\hline HLA class I & $P<0.0001$ & $P<0.0001$ \\
\hline Negative & $0 \%$ & $0 \%$ \\
\hline Low & $77.8 \%$ & $33.3 \%$ \\
\hline High & $100 \%$ & $66.1 \%$ \\
\hline Age & $P=0.93$ & $P=0.89$ \\
\hline$\leq 14$ years & $83.3 \%$ & $33.3 \%$ \\
\hline$>14$ years & $60.4 \%$ & $44.4 \%$ \\
\hline Sex & $P=0.023$ & $P=0.001$ \\
\hline Male & $80.9 \%$ & $51.9 \%$ \\
\hline Female & $0 \%$ & $0 \%$ \\
\hline Tumor site & $P=0.60$ & $P=0.081$ \\
\hline Lower femur & $85.7 \%$ & $38.1 \%$ \\
\hline Middle femur & $0 \%$ & $0 \%$ \\
\hline Upper tibia & $58.3 \%$ & $66.7 \%$ \\
\hline Tumor stage & $P<0.0001$ & $P<0.0001$ \\
\hline Localized & $96.3 \%$ & $51.9 \%$ \\
\hline Metastatic & $0 \%$ & $0 \%$ \\
\hline Histopathological variant & $P=0.13$ & $P=0.413$ \\
\hline Osteoblastic & $39.3 \%$ & $50 \%$ \\
\hline Chondroblastic & $37.5 \%$ & $25 \%$ \\
\hline Fibroblastic & $100 \%$ & $55.6 \%$ \\
\hline Small cell type & $100 \%$ & $0 \%$ \\
\hline Tumor necrosis & $P=0.017$ & $P<0.0001$ \\
\hline Poor response (<90\%) & $32.7 \%$ & $12.5 \%$ \\
\hline Good response $(\geq 90 \%)$ & $100 \%$ & $91.7 \%$ \\
\hline
\end{tabular}

with low expression of HLA class I showed a significantly longer disease-free survival when compared to those with negative expression. When excluding patients presented with metastatic disease, there were still a significant differences between HLA class I expression, on the one hand, and overall $(\mathrm{P}=.018)$ and disease free survival $(\mathrm{P}=.001)$, on the other.

In univariate analysis of overall and disease-free survival with clinicopathological parameters (Table 2), the only parameters that reached a statistical significance for overall and disease-free survival were the sex of the patients ( $\mathrm{P}=.02$ and $\mathrm{P}=.001$ respectively), tumor stage at time of diagnosis, $(\mathrm{P}=.0001$ for both) and extent of tumor necrosis $(\mathrm{P}=.017$ and $\mathrm{P}=.0001$ respectively). Among female patients included in this study, poor response to preoperative chemotherapy together with metastatic stage at time of diagnosis were associated significantly with shorter overall and disease-free survival when compared to male patients, localized stage at presentation and good response to preoperative chemotherapy.

Using the backward stepwise Cox regression analysis, multivariate analyses were performed to determine the variables that were independently predictive of overall survival. As illustrated in Table 3 with adjustment of sex, tumor necrosis and HLA class I expression, metastatic stage at time of diagnosis was the only independent prognostic factor for decreased overall survival that reached a significant level (Hazard ratio $=30.086, \mathrm{P}=.002$ ). However, the other variables lost their significance at multivariate analysis. Subsequent Cox regression analysis for diseasefree survival (Table 3) confirmed that poor response to preoperative chemotherapy (Hazard ratio $=19.031, \mathrm{P}=.007$ ) and negative HLA class I expression (Hazard ratio $=19.125$, $\mathrm{P}=.001$ ) were independent predictors for decreased diseasefree survival. Variable HLA expression is illustrated in Figure 3.

\section{Discussion}

Evasion of anti-tumor immunity has been thought to be critical to progress of cancers. Several studies have shown that down-regulation of HLA class I expression is observed in various tumor cells and it would cause a malignant phenotype. It is possible that, in the process of tumor extension, tumors that lost HLA class I survived and escaped from antigen-specific CTL-mediated lysis leading to tumor dissemination and metastasis. Patients with positive HLA class I expression showed a better DFS (disease free survival) in comparison with those with down regulation of HLA class I expression. Our result differs from some studies of esophageal cancer [34] and malignant melanoma [37] that have shown a lack of prognostic significance for HLA class I expression. Total loss of HLA class I was proposed as an indicator of good prognosis in breast cancer and non-small-cell lung cancer [38]. In those reports, the authors mentioned that HLA class I antigen down-regulation may make the tumors more susceptible to natural killer (NK) cell killing and result in a better prognosis. The results of the current study suggest that HLA class I expression may be one of the important prognostic factors in osteosarcoma and an important factor to select proper patients for treatment with CTL-based immunotherapy in the future.

It has been demonstrated that human tumors with various histology have low or down regulated HLA class I molecules due to the modulation or inhibition of the expression of various HLA class I antigen-processing machinery (APM) components. It is well known that abnormality of HLA class I molecules and APM in tumor cells is one of the major reasons for escape from CD8 $(+)$ cytotoxic $\mathrm{T}$ cells, resulting in disease progression [39]. Moreover, tumor cells showing the down regulation of specific HLA class I alleles could escape from T-cell- 


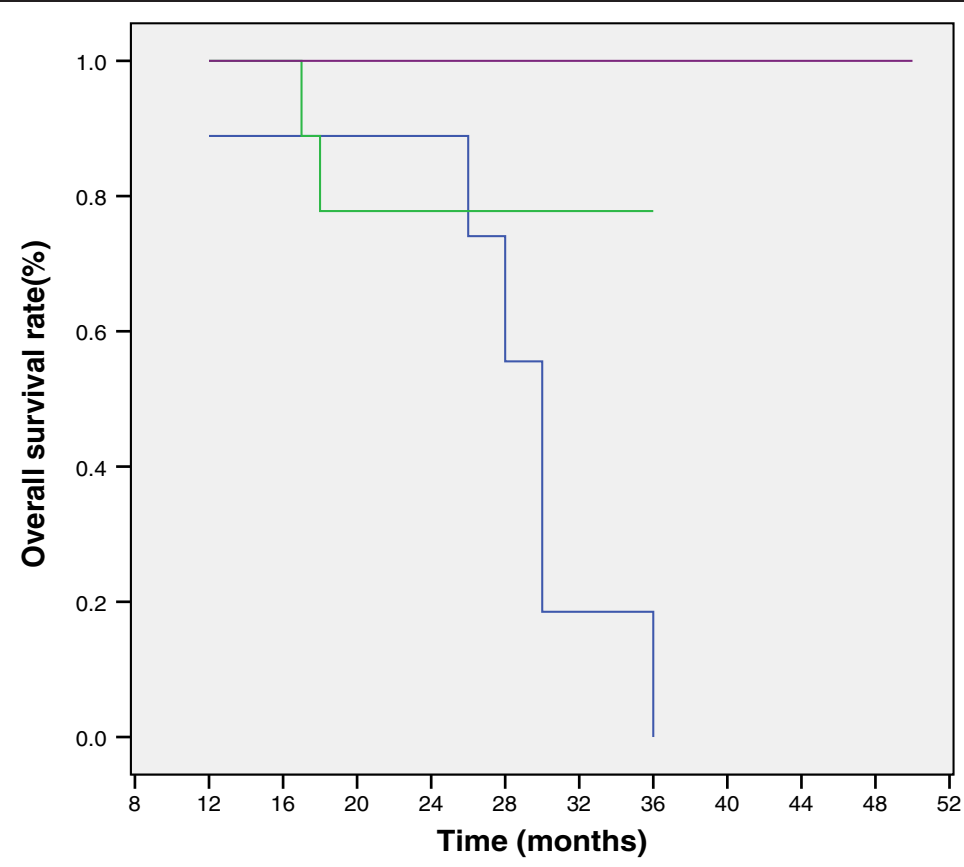

HLA expression

$\neg$ Negative

$\neg$ Low

Figure 1 Kaplan-Meier overall survival curve in relation to immunohistochemistry scores for HLA class I.

mediated immunity and also avoid NK cell-mediated killing due to sufficient HLA class I expression [40].

The monoclonal antibody EMR8-5 can recognize all of HLA A, B, and C heavy chain even in formalin-fixed tissue. In this context, EMR8-5 can recognize whole HLA molecules, and its validity was supported by the immunostaining performed in our study. Some authors reported that HLA class I positivity examined using the conventional HLA class I antibody W6/32, which also recognizes all HLA class I antigens, was 30\% of HLA class I positivity in breast cancer, similar to that shown in our present study [38,41]. In contrast, Madjd et al.

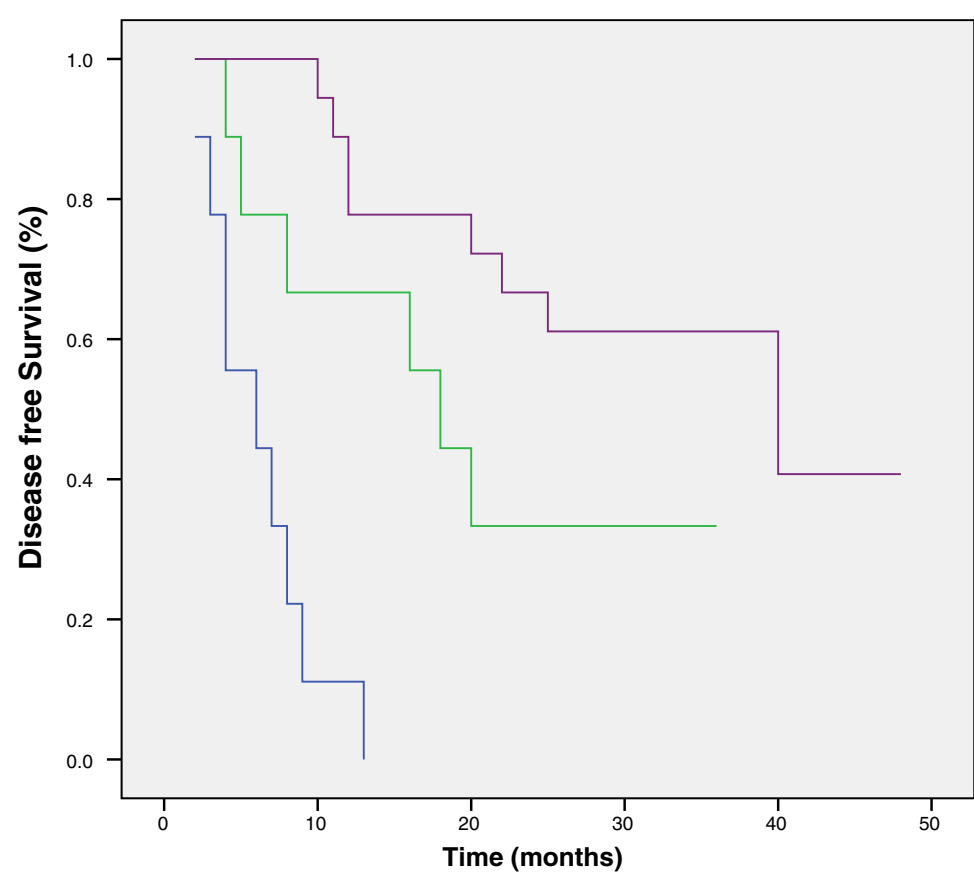

HLA expression 
Table 3 Multivariate analysis for studying the effect of independent factors on overall survival and disease free survival

\begin{tabular}{|c|c|c|c|c|c|}
\hline & \multirow[t]{2}{*}{ HR } & \multirow[t]{2}{*}{$\mathbf{P}$} & \multirow[t]{2}{*}{ Sig } & \multicolumn{2}{|c|}{$95 \% \mathrm{Cl}$ of $\mathrm{HR}$} \\
\hline & & & & Lower & Upper \\
\hline \multicolumn{6}{|l|}{ Overall survival } \\
\hline Tumor stage at time of diagnosis (localized versus metastatic stage) & 30.086 & 0.002 & HS & 3.665 & 246.990 \\
\hline \multicolumn{6}{|l|}{ Disease free survival } \\
\hline Female sex versus male sex & 1.611 & 0.538 & NS & 0.353 & 7.351 \\
\hline Localized stage at time of diagnosis versus metastatic stage & 3.220 & 0.087 & NS & 0.845 & 12.263 \\
\hline Tumor necrosis (good response versus poor response) & 19.031 & 0.007 & HS & 2.274 & 159.236 \\
\hline Low HLA class I expression versus high & 1.475 & 0.673 & NS & 0.243 & 8.971 \\
\hline Negative HLA class I expression versus high & 19.125 & 0.001 & $\mathrm{HS}$ & 3.359 & 108.906 \\
\hline
\end{tabular}

investigated HLA class I expression in breast cancer using a $\mathrm{HC}-10$ antibody [38], and demonstrated that HLA class I negativity correlated with a better postoperative outcome. These results conflicted with the data in our study. This discrepancy may be explained by the fact that whereas the HC10 mAb scarcely reacts with HLA-A alleles, the anti- HLA class I heavy chain mAb EMR8-5 can detect all recombinant proteins of HLA-A, B, and $\mathrm{C}$ alleles [42]. In addition, EMR8-5 can be applied to paraffin-fixed specimens, so in this context it is an ideal antibody for evaluating cancerous HLA class I antigen expression.

In the present study, down-regulation of HLA class I expression represented an independent factor associated with poor prognosis in pretreatment biopsy of nonlocalized osteosarcoma. The down regulation of HLA class I expression was significantly associated with lymphatic and nodal invasion in studies conducted by Kaneko and his colleagues [35]. Therefore, cancerous HLA class I down regulation seems to be conducive to metastasis to other organs. Other studies reported the down regulation of HLA class I expression in breast cancer [43], esophageal cancer [34], and lung cancer [26]. The degree of HLA class I loss may be affected by organ specificity. Watson et al. (2006) reported that patients who had colon cancer with low-level expression of HLA class I displayed significantly worse prognosis compared with those with HLA class I-positive cancer consistent with the results of the current study [32]. The only research work, in addition to this research, that performed osteosarcoma tissue blocks by immunohistochemistry is in agreement consistently with our findings as the researchers declared that patients with osteosarcoma exhibiting high expression of HLA class I showed significantly better overall and event-free survival compared to those with HLA class I-negative osteosarcoma [44].

Another recent study showed that osteosarcoma tissues with high expression of SOX9, a developmental transcription factor, tend to have shorter overall survival and disease-free survival [45]. Combining SOX9 and HLA EMR8-5 in a large scale study can probably prove their high prognostic value in osteosarcoma. Another promising marker is Aurora Kinase A and B that has proven to be correlated with poor outcome in patient with chondrosarcoma [46]. However, the only research applied for Aurora Kinase A and B on osteosarcoma was in vitro, thus further investigation may evolve a new prognostic marker.

Multivariate analysis showed a significant adverse effect on prognosis for metastatic tumors at time of initial diagnosis. Regarding the prognostic significance of age, a better prognosis for younger patients has been reported [47], whereas other authors found a better prognosis for older patients [18]. Prognostic significance of alkaline phosphatase in osteosarcoma was previously documented [20]. Furthermore, tumors of distal upper limb are associated with better survival [24], whereas tumors in proximal femur or humerus have been reported to have poorer prognoses than those on the sides of knee joints [21]. In our cohort, no significant results were obtained in correlation with age, alkaline phosphatase, or tumor location. Nonetheless, due to different criteria of inclusion, a reliable comparison between studies is impossible.

As the down regulation of HLA class I expression frequently occurred in OS, the preservation of HLA class I expression on tumors might be one of the inclusion criteria for cancer vaccination therapy for OS. Furthermore, the treatment strategy aiming at restoring HLA class I expression could be able to improve survival among patients with OS or could lead to successful immunotherapy.

\section{Conclusion}

The status of HLA class I expression affected the overall survival and disease-free survival of patients with osteosarcoma. Down-regulation of HLA class I expression in osteosarcoma represents a marker of poor prognosis, and may play a critical role in immune surveillance of patients with osteosarcoma. The present results provide critical information for successful immunotherapy against osteo- 

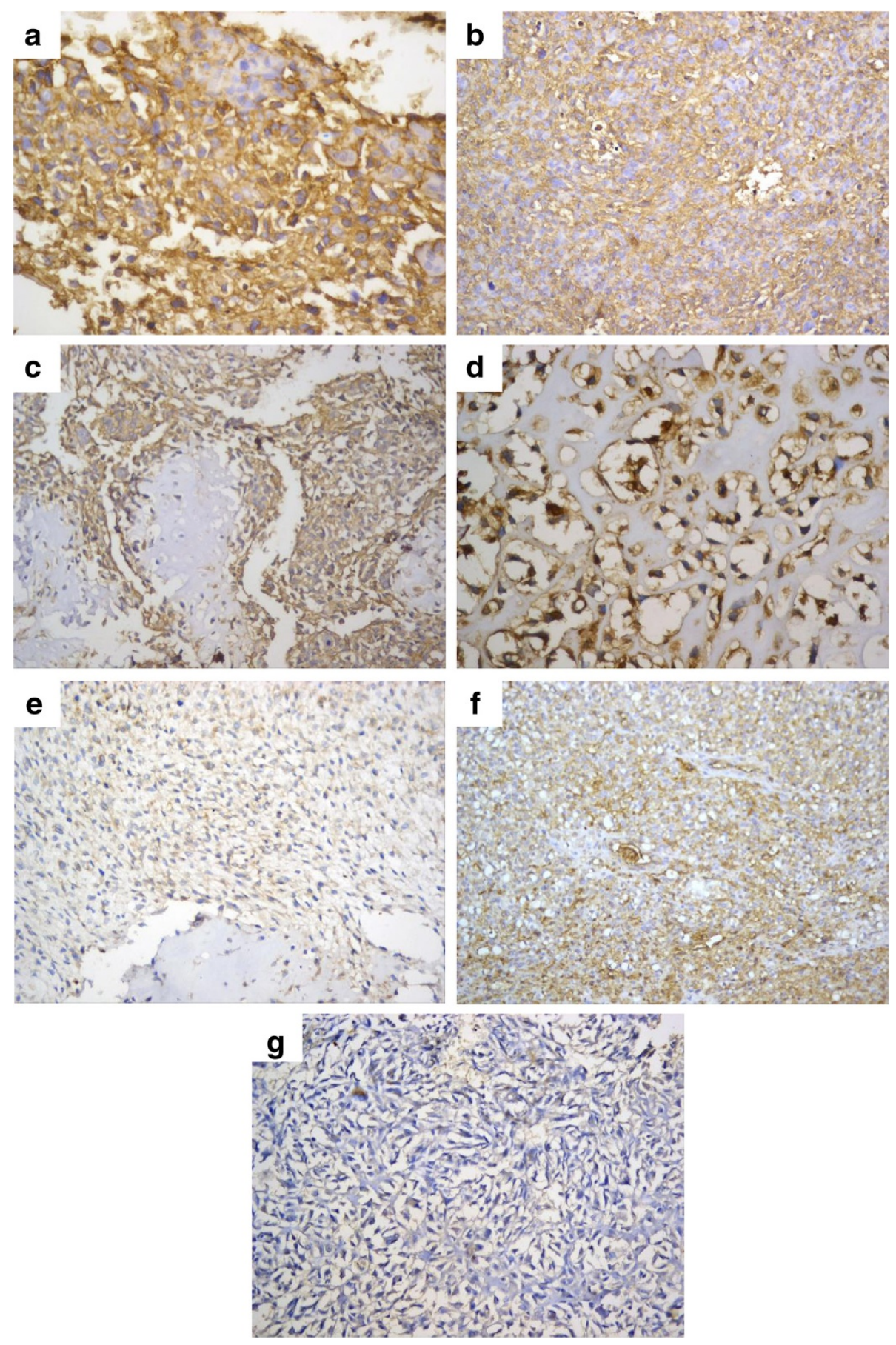

Figure 3 Representative images of immunohistochemical staining of primary osteosarcoma with HLA Class I EMR8-5 Sections: a, b, c and d: Sections from cases showing strongly positive expression of HLA class I with diffuse staining in $>50 \%$ of tumor cells in a conventional osteosarcoma ( $a$, b: immonoperoxidase $\times 400$ and $\times 200$ respectively) and chondroblastic osteosarcoma with well evident membranous immunostaining of malignant cells (c, d: immonoperoxidase $x 400)$. e and $\mathbf{f}$ : Sections from cases with low positive and heterogeneous expression of HLA class I, respectively, showed areas with both strongly positive and negative expression of HLA class I (immonoperoxidase x200). g: Sections from a case with negative expression of HLA class I (immonoperoxidase $\times 200$ ).

sarcoma. However, because of the limited number of cases in our work which are compiled from a single institute, larger studies with multi-institutional collaboration are recommended to validate the significance of HLA class I expression as a prognostic factor and the rational application of immunotherapy for patients with osteosarcoma. 


\section{Abbreviations}

OS: Osteosarcoma; HLA: Human leukocyte antigen; CTLs: Cytotoxic T lymphocytes; DFS: Disease free survival.

\section{Competing interests}

The authors declared that they have no competing interests.

\section{Authors' contributions}

ON designed the study, wrote the protocol, monitored the immunohistochemical staining and wrote the first draft of the manuscript. NA and HAG performed the statistical analysis and managed the analyses of the study. All authors scored the immunostaining, read and approved the final manuscript.

\section{Author details}

${ }^{1}$ Department of pathology, faculty of Medicine, Ain Shams university, Cairo, Egypt. ${ }^{2}$ Department of pathology, faculty of Medicine, Ain Shams university, Cairo, Egypt. ${ }^{3}$ Department of pathology, faculty of Medicine, Ain Shams university, Cairo, Egypt.

Received: 8 October 2013 Accepted: 18 March 2014

Published: 25 March 2014

\section{References}

1. Marina N, Gebhardt M, Teot L, Gorlick R: Biology and therapeutic advances for Pediatric osteosarcoma. Oncologist 2004, 9(4):422-441.

2. Fagioli F, Biasin E, Mereuta OM, Muraro M, Luksch R, Ferrari S, Aglietta M, Madon E: Poor prognosis osteosarcoma: new therapeutic approach. Bone Marrow Transplant 2008, 41(Suppl 2):S131-S134.

3. Haydon RC, Luu HH, He TC: Osteosarcoma and osteoblastic differentiation: a new perspective on oncogenesis. Clin Orthop Relat Res 2007, 454:237-246.

4. Kansara M, Thomas DM: Molecular pathogenesis of osteosarcoma. DNA Cell Biol 2007, 26(1):1-18

5. Ritter J, Bielack SS: Osteosarcoma. Ann Oncol 2010, 21(7):vii: 320-vii: 325

6. Sakamoto A, Iwamoto $Y$ : Current status and perspectives regarding the treatment of osteo-sarcoma: chemotherapy. Rev Recent Clin Trials 2008, 3(3):228-231.

7. Lamoureux F, Trichet V, Chipoy C, Blanchard F, Gouin F, Redini F: Recent advances in the management of osteosarcoma and forthcoming therapeutic strategies. Expert Rev Anticancer Ther 2007, 7(2):169-181.

8. Klein MJ, Siegal GP: Osteosarcoma: anatomic and histologic variants. Am J Clin Pathol 2006, 125:555-581.

9. Fletcher C, Unni K, Mertens F: Conventional Osteosarcoma. In Pathology and Genetics of Tumors of Soft Tissue and Bone. 4th edition. Lyon, France: IARC Press; 2013

10. Chou AJ, Gorlick R: Chemotherapy resistance in osteosarcoma: current challenges and future directions. Expert Rev Anticancer Ther 2006, 6 (7):1075-1085

11. Mialou V, Philip T, Kalifa C, Perol D, Gentet JC, Marec-Berard P, Pacquement $\mathrm{H}$, Chastagner P, Defaschelles AS, Hartmann O: Metastatic osteosarcoma at diagnosis: prognostic factors and long-term outcome-the French pediatric experience. Cancer 2005, 104(5):1100-1109.

12. Longhi A, Errani C, De Paolis M, Mercuri M, Bacci G: Primary bone osteosarcoma in the pediatric age: state of the art. Cancer Treat Rev 2006, 32(6):423-436.

13. Picci P: Osteosarcoma (osteogenic sarcoma). Orphanet J Rare Dis 2007, 2:6.

14. Souhami RL, Craft AW, Van der Eijken JW, Nooij M, Spooner D, Bramwell VH, Wierzbicki R, Malcolm AJ, Kirkpatrick A, Uscinska BM, Van Glabbeke M, Machin D: Randomized trial of two regimens of chemotherapy in operable osteosarcoma: a study of the European Osteosarcoma Intergroup. Lancet 1997, 350(9082):911-917.

15. Schwartz CL, Gorlick R, Teot L, Krailo M, Chen Z, Goorin A, Grier HE, Bernstein ML, Meyers P: Children's Oncology Group. Multiple drug resistance in osteogenic sarcoma: INT0133 from the Children's Oncology Group. J Clin Oncol 2007, 25(15):2057-2062.

16. Tan ML, Choong PF, Dass CR: Osteosarcoma: Conventional treatment vs. gene therapy. Cancer Biol Ther 2009, 8(2):106-117.

17. Kempf-Bielack B, Bielack SS, Jürgens H, Branscheid D, Berdel WE, Exner GU, Göbel U, Helmke K, Jundt G, Kabisch H, Kevric M, Klingebiel T, Kotz R, Maas R, Schwarz R, Semik M, Treuner J, Zoubek A, Winkler K: Osteosarcoma relapse after combined modality therapy: an analysis of unselected patients in the Cooperative Osteosarcoma Study Group (COSS). J Clin Oncol 2005, 23(3):559-568.

18. Carsi B, Rock MG: Primary osteosarcoma in adults older than 40 years. Clin Orthop Relat Res 2002, 397:53-61.

19. Heck RK Jr, Stacy GS, Flaherty MJ, Montag AG, Peabody TD, Simon MA: A comparison study of staging systems for bone sarcomas. Clin Orthop Relat Res 2003, 415:64-71.

20. Bacci G, Longhi A, Versari M, Mercuri M, Briccoli A, Picci P: Prognostic factors for osteosarcoma of the extremity treated with neoadjuvant chemotherapy: 15-year experience in 789 patients treated at a single institution. Cancer 2006, 106(5):1154-1161.

21. Bielack SS, Kempf-Bielack B, Delling G, Exner GU, Flege S, Helmke K, Kotz R, Salzer-Kuntschik M, Werner M, Winkelmann W, Zoubek A, Jürgens H, Winkler K: Prognostic factors in high-grade osteosarcoma of the extremities or trunk: an analysis of 1,702 patients treated on neoadjuvant cooperative osteosarcoma study group protocols. J Clin Oncol 2002, 20(3):776-790.

22. Grimer RJ, Taminiau AM, Cannon SR: Surgical Subcommitte of the European Osteosarcoma Intergroup. Surgical outcomes in osteosarcoma. J Bone Joint Surg (Br) 2002, 84(3):395-400.

23. Bacci $G$, Longhi $A$, Ferrari $S$, Lari $S$, Manfrini M, Donati D, Forni C, Versari M: Prognostic significance of serum alkaline phosphatase in osteosarcoma of the extremity treated with neoadjuvant chemotherapy: recent experience at Rizzoli Institute. Oncol Rep 2002, 9(1):171-175.

24. Kim MS, Lee SY, Lee TR, Cho WH, Song WS, Koh JS, Lee JA, Yoo JY, Jeon DG: Prognostic nomogram for predicting the 5 -year probability of developing metastasis after neo-adjuvant chemotherapy and definitive surgery for AJCC stage II extremity osteosarcoma. Ann Oncol 2009, 20(5):955-960.

25. Yang C, Ji D, Weinstein EJ, Choy E, Hornicek FJ, Wood KB, Liu X, Mankin H, Duan Z: The kinase Mirk is a potential therapeutic target in osteosarcoma. Carcinogenesis 2010, 31(4):552-558.

26. Kikuchi E, Yamazaki K, Torigoe T, Cho Y, Miyamoto M, Oizumi S, Hommura F, Dosaka-Akita H, Nishimura M: HLA class I antigen expression is associated with a favorable prognosis in early stage non-small cell lung cancer. Cancer Sci 2007, 98(9):1424-1430.

27. Homma I, Kitamura H, Torigoe T, Tanaka T, Sato E, Hirohashi Y, Masumori N, Sato N, Tsukamoto T: Human leukocyte antigen class I down-regulation in muscle-invasive bladder cancer: its association with clinical characteristics and survival after cystectomy. Cancer Sci 2009, 100(12):2331-2334.

28. Bubeník J: MHC class I down-regulation: tumor escape from immune surveillance? (Review). Int J Oncol 2004, 25(2):487-491.

29. Hosch SB, Izbicki JR, Pichlmeier U, Stoecklein N, Niendorf A, Knoefel WT, Broelsch CE, Pantel K: Expression and prognostic significance of immunoregulatory molecules in esophageal cancer. Int J Cancer 1997 74:582-587.

30. Kageshita T, Hirai S, Ono T, Hicklin DJ, Ferrone S: Down-regulation of HLA class I antigen-processing molecules in malignant melanoma: association with disease progression. Am J Pathol 1999, 154(3):745-754.

31. Vitale M, Pelusi G, Taroni B, Gobbi G, Micheloni C, Rezzani R, Donato F, Wang X, Ferrone S: HLA class I antigen down-regulation in primary ovary carcinoma lesions: association with disease stage. Clin Cancer Res 2005, 11(1):67-72

32. Watson NF, Ramage JM, Madjd Z, Spendlove I, Ellis IO, Scholefield JH, Durrant LG: Immunosurveillance is active in colorectal cancer as downregulation but not complete loss of MHC class I expression correlates with a poor prognosis. Int J Cancer 2006, 118(1):6-10.

33. Kitamura H, Honma I, Torigoe T, Asanuma H, Sato N, Tsukamoto T: Down-regulation of HLA class I antigen is an independent prognostic factor for clear cell renal cell carcinoma. J Urol 2007, 177(4):1269-1272.

34. Mizukami $Y$, Kono K, Maruyama T, Watanabe M, Kawaguchi $Y$, Kamimura $\mathrm{K}$, Fujii H: Downregulation of HLA Class I molecules in the tumor is associated with a poor prognosis in patients with oesophageal squamous cell carcinoma. Br J Cancer 2008, 99(9):1462-1467.

35. Kaneko K, Ishigami S, Kijima Y, Funasako Y, Hirata M, Okumura H, Shinchi $H_{\text {, }}$ Koriyama C, Ueno S, Yoshinaka H, Natsugoe S: Clinical implication of HLA class I expression in breast cancer. BMC Cancer 2011, 11:454.

36. Al-Batran SE, Rafiyan MR, Atmaca A, Neumann A, Karbach J, Bender A, Weidmann E, Altmannsberger HM, Knuth A, Jäger E: Intratumoral T-cell infiltrates and MHC class I expression in patients with stage IV melanoma. Cancer Res 2005, 65(9):3937-3941. 
37. Kamarashev J, Ferrone S, Seifert B, Böni R, Nestle FO, Burg G, Dummer R: TAP1 down-regulation in primary melanoma lesions: an independent marker of poor prognosis. Int J Cancer 2001, 95(1):23-28

38. Madjd Z, Spendlove I, Pinder SE, Ellis IO, Durrant LG: Total loss of MHC class I is an independent indicator of good prognosis in breast cancer. Int J Cancer 2005, 117(2):248-255.

39. Seliger B: Molecular mechanisms of MHC class I abnormalities and APM components in human tumors. Cancer Immunol Immunother 2008, 57(11):1719-1726.

40. Garrido F, Ruiz-Cabello F, Cabrera T, Pérez-Villar JJ, López-Botet M, Duggan-Keen M, Stern PL: Implications for immunosurveillance of altered HLA class I phenotypes in human tumors. Immunol Today 1997, 18:89-95.

41. Torigoe T, Asanuma H, Nakazawa E, Tamura Y, Hirohashi Y, Yamamoto E, Kanaseki T, Hasegawa T, Sato N: Establishment of a monoclonal anti-pan HLA class I antibody suitable for immunostaining of formalin-fixed tissue: unusually high frequency of down-regulation in breast cancer tissues. Pathol Int 2012, 62(5):303-308.

42. Sato N, Hirohashi Y, Tsukahara T, Kikuchi T, Sahara H, Kamiguchi K, Ichimiya S, Tamura Y, Torigoe T: Molecular pathological approaches to human tumor immunology. Pathol Int 2009, 59(4):205-217.

43. Ishigami S, Natsugoe S, Nakajo A, Arigami T, Kitazono M, Okumura H, Matsumoto M, Uchikado Y, Setoyama T, Sasaki K, Aikou T: HLA-class I expression in gastric cancer. J Surg Oncol 2008, 97(7):605-608.

44. Tsukahara T, Kawaguchi S, Torigoe T, Asanuma H, Nakazawa E, Shimozawa K, Nabeta Y, Kimura S, Kaya M, Nagoya S, Wada T, Yamashita T, Sato N: Prognostic significance of HLA class I expression in osteosarcoma defined by anti-pan HLA class I monoclonal antibody, EMR8-5. Cancer Sci 2006, 97(12):1374-1380.

45. Zhu H, Tang J, Tang M, Cai H: Up regulation of SOX9 in osteosarcoma and its association with tumor progression and patients' prognosis. Diagn Pathol 2013, 8(1):183.

46. Liang $X$, Wang D, Wang Y, Zhou Z, Zhang J, Li J: Expression of aurora kinase $A$ and $B$ in chondrosarcoma and its relationship with the prognosis. Diagn Pathol 2012, 7:84.

47. Winkler K, Beron G, Kotz R, Salzer-Kuntschik M, Beck J, Beck W, Brandeis W Ebell W, Erttmann R, Göbel U: Neoadjuvant chemotherapy for osteogenic sarcoma: results of a Cooperative German/Austrian study. J Clin Oncol 1984, 2(6):617-624.

doi:10.1186/1746-1596-9-72

Cite this article as: Nada et al.: Prognostic significance of HLA EMR8-5 immunohistochemically analyzed expression in osteosarcoma. Diagnostic Pathology 2014 9:72.

\section{Submit your next manuscript to BioMed Central and take full advantage of:}

- Convenient online submission

- Thorough peer review

- No space constraints or color figure charges

- Immediate publication on acceptance

- Inclusion in PubMed, CAS, Scopus and Google Scholar

- Research which is freely available for redistribution 